\title{
The prevalence of antimicrobial resistance and carriage of virulence genes in Staphylococcus aureus isolated from food handlers in Kuwait City restaurants Edet E Udo*1, Siham Al-Mufti ${ }^{2}$ and M John Albert ${ }^{1}$
}

Address: ${ }^{1}$ Department of Microbiology, Faculty of Medicine, Kuwait University, Kuwait and ${ }^{2}$ Public Health Laboratory, Ministry of Health, Kuwait Email: Edet E Udo* - edet@hsc.edu.kw; Siham Al-Mufti - Sihmufti@kuwait.net; M John Albert - John@hsc.edu.kw

* Corresponding author

Published: 16 June 2009

BMC Research Notes 2009, 2:108 doi:10.1/86/1756-0500-2-108

This article is available from: http://www.biomedcentral.com//756-0500/2//08

(C) 2009 Udo et al; licensee BioMed Central Ltd.

This is an Open Access article distributed under the terms of the Creative Commons Attribution License (http://creativecommons.org/licenses/by/2.0), which permits unrestricted use, distribution, and reproduction in any medium, provided the original work is properly cited.

\begin{abstract}
Background: Staphylococcus aureus is a major cause of food poisoning due to their ability to produce enterotoxins which if ingested in sufficient amounts results in sickness. Food handlers carrying enterotoxin-producing $S$. aureus in their noses or hands can contaminate food leading to food poisoning. We characterized $200 \mathrm{~S}$. aureus obtained from food handlers in different restaurants for antibacterial resistance and the carriage of virulence genes.
\end{abstract}

Findings: Susceptibility to antibacterial agents was determined by disk diffusion and Etest. PCR was used to detect genes for accessory gene regulator (agr); capsular polysaccharide (cap) 5 and 8 , staphylococcal enterotoxins (SE), toxic shock syndrome toxin-I (TSST-I) and Panton-Valentine leukocidin (PVL). Isolates were typed using pulsed-field gel electrophoresis. In total 185 (92.5\%) of the 200 isolates expressed resistance to antibacterial agents. They were resistant to penicillin G $(82.0 \%)$, tetracycline (19.0\%), erythromycin (2.5\%), clindamycin (2.0\%), trimethoprim $(7.5 \%)$, kanamycin (2.5\%), streptomycin (1.5\%), ciprofloxacin (1.5\%), fusidic acid (I.0\%) and cadmium acetate (68.0\%). Seventy-six (38.0\%) and II $4(57.0 \%)$ isolates had type 5 and type 8 capsular polysaccharides respectively. The agr types I, II and III alleles were detected in $50.5 \%, 20.0 \%$ and $23.5 \%$ of the isolates respectively. They contained genes for SEI (38.5\%), SEG (24.0\%), SEC (23.0\%), SEB (I2.5\%), SEH (2I.5\%), SEA (I I.0), SED (I.5\%), SEE (I.5\%), TSST-I (4.0\%) and PVL ( $9.0 \%)$.

Conclusion: This study revealed a high prevalence of antibacterial resistance and virulence determinants in S. aureus from food handlers in Kuwait restaurants justifying the screening of food handlers to detect and treat carriers and protect restaurant customers from staphylococcal food poisoning.

\section{Background}

Staphylococcus aureus can cause localized and invasive infections in humans. This is attributed to its ability to produce a variety of virulence factors such as capsular polysaccharides, staphylococcal enterotoxins (SEs), toxic shock syndrome toxin 1 (TSST-1) [1,2], panton - valentine leukocidin (PVL) [3] and accessory gene regulators (agr) [1,4-6]. Although S. aureus isolates produce one of 11 serotypes of capsular polysaccharides, most clinical isolates belong to serotypes 5 and 8 [2]. Enterotoxin-producing $S$. aureus are common causes of food poisoning in many parts of the world. The ingestion of the preformed toxins in food often leads to the development of food poisoning. The symptoms typically have a rapid onset (2-6 
h) and may include nausea, vomiting, diarrhea and abdominal pain [1]. Nasal and hand carriage of enterotoxigenic $S$. aureus by food handlers is an important source of staphylococcal food contamination in restaurants and fast food outlets [7]. Therefore it is important to detect $S$. aureus carriage among food handlers to prevent possible food contamination by them resulting in food poisoning.

Food poisoning outbreaks result in huge financial losses to restaurants, in addition to the loss of reputation and confidence among the public. Staphylococcal food-borne diseases are estimated to cause $6-81$ million illnesses and up to 9000 deaths, and accounts for $14-20 \%$ of outbreaks involving contaminated food in the USA [8].

Most of the studies on S. aureus associated with food poisoning have focused on screening of the isolates for enterotoxins [1,9-13] with only sparse data on the carriage of other virulence factors and antimicrobial resistance among S. aureus obtained from food handlers [14-17] especially in the Arabian Gulf countries. Although we previously studied the prevalence of staphylococcal enterotoxins in S. aureus isolated from food handlers in Kuwait city [10], their susceptibility to antibacterial agents were not investigated. Therefore in the present study, we characterized S. aureus isolated from food handlers in Kuwait City restaurants for their susceptibility to antibacterial agents and the carriage of virulence associated genes.

\section{Methods}

\section{S. aureus isolates}

In total, $200 \mathrm{~S}$. aureus isolates were recovered from food handlers working in 50 Kuwait City restaurants from 2003 to 2005. They consisted of 133 (102 isolates from nasal and 31 hand swabs) of 500 swabs from 250 adult male workers in 50 restaurants, during screening of food handlers as demanded by the City Council, yielding a carriage rate of 53.2\%. The Kuwait Municipal Council mandated a compulsory screening of restaurant workers to detect $S$. aureus carriers. Only one sample was investigated from the same food handler. The study also included 67 isolates obtained from 31 stool samples, 9 throat swabs and 27 nasal samples obtained from food handlers during routine investigations of suspected cases of food poisoning in different restaurants. Bacteria were isolated and identified using standard bacteriological methods including cultural characteristics, Gram stain, catalase, tube coagulase and DNase tests [10]. The isolates were preserved in skimmed milk at $-80^{\circ} \mathrm{C}$.

\section{Susceptibility to antibacterial agents}

Susceptibility to antimicrobial agents was determined by the disk diffusion method [18] Disks containing cadmium acetate $(50 \mu \mathrm{g})$, propamidine isethionate $(100 \mu \mathrm{g})$, and mercuric chloride $(109 \mu \mathrm{g})$ were prepared in the lab- oratory [19]. A zone diameter of $6-10 \mathrm{~mm}$ indicated resistance to cadmium acetate, propamidine isethionate and mercuric chloride. The minimum inhibitory concentrations (MICs) of methicillin, vancomycin and teicoplanin were determined with Etest strips (AB Biodisk, Solna, Sweden) according to the manufacturer's instructions. S. aureus strain ATCC25923 was used for quality control.

\section{Isolation of DNA for PCR amplification}

DNA for PCR was extracted as described previously [3]. The extracted DNA was used for PCR immediately or stored at $4{ }^{\circ} \mathrm{C}$ and used within three months.

\section{Detection of genes for staphylococcal enterotoxin (SE)} and toxic shock syndrome toxin (TSST-I)

PCR amplification was performed for genes encoding staphylococcal enterotoxins SEA (sea), SEB (seb), SEC (sec), SED (sed), SEE (see), SEG(seg), SEH (seh), and SEI (sei) and toxic shock syndrome gene TSST-1(tst) with primers published previously $[13,20]$ in three multiplex (MT) assays as follows: MT1 (sec, sei and sed), MT 2 (seg, seh and see) and MT 3 (sea, seb and tst). Based on optimization experiments, the primer concentrations used were $0.1 \mu \mathrm{M}$ for sea, sec, and tst, and $0.2 \mu \mathrm{M}$ for seb, see, sed, seg and seh. Amplifications comprised an activation step at $95^{\circ} \mathrm{C}$ for $15 \mathrm{~min}$ followed by 37 cycles of $94^{\circ} \mathrm{C}$ for $2 \mathrm{~min}, 51^{\circ} \mathrm{C}$ for $1 \mathrm{~min}$ and $72^{\circ} \mathrm{C}$ for $1 \mathrm{~min}$ with a final extension at $72^{\circ} \mathrm{C}$ for $7 \mathrm{~min}$. Control strains used were $S$. aureus; ATCC13565 (SEA), ATCC14458 (SEB), ATCC23235 (SED), ATCC27664 (SEE), ATCC51811 (SEH), WBG525 (SEC, TSST-1), C90 (SEI) [16], C29 (SEG). The 16S rRNA primers, 5'-GGA GGA AGG TGG GGA TGA CG-3' and 5'ATG GTG TGA CGG GCG GTG TG-3' [21] were used as internal controls. All tests were considered positive if the positive controls and the internal controls yielded the expected results. Negative controls for all PCR consisted of the PCR mixes without template DNA. PCR products (5 $\mu \mathrm{l})$ were loaded in $2.0 \%(\mathrm{w} / \mathrm{v})$ molecular biology grade agarose (BioRad, Hercules, USA) gels. PCR products were analyzed by agarose gel electrophoresis.

\section{Detection of genes for accessory gene regulators (agr), capsular polysaccharides (cap) and Panton-Valentine Leucocidin (lukS-lukF)}

All isolates were tested for the presence of genes for PVL, agr types I, II, III and IV and cap type 5 and type 8 in PCR assays as described previously $[3,22,23]$. The $16 \mathrm{~S}$ rRNA primer [21] was used as internal control in PCR amplifications.

\section{Pulsed-field gel electrophoresis (PFGE)}

Counter-clamped homogeneous electric field (CHEF) electrophoresis of Sma I-digested chromosomal DNA was performed as described previously [19]. 


\section{Statistics}

Differences in the distribution of virulence determinants between groups were assessed by Chi square test. A Pvalue of $=0.05$ was considered significant.

\section{Results}

One hundred and eighty five (92.5\%) of the 200 S. aureus isolates were resistant to antibacterial agents. The majority, $164(82.0 \%)$ and $136(68.0 \%)$ of them were resistant to penicillin $\mathrm{G}$ and cadmium acetate respectively. Fortytwo isolates $(21.0 \%)$ were resistant to tetracycline, 15 isolates $(7.5 \%)$ were resistant to trimethoprim and six isolates $(3 \%)$ were resistant to kanamycin. Five and four isolates were resistant to erythromycin and streptomycin respectively. Two isolates were resistant to fusidic acid and only one isolate was resistant to methicillin and gentamicin. They were all susceptible to mupirocin, rifampicin, vancomycin, teicoplanin and linezolid. Sixtyfive percent of them were resistant to two or more antibacterial agents and 23\% were multiresistant with resistance to three or more classes of antibacterial agents.

The distribution of genes for capsular types and agr allotypes is summarized in Table 1. Whereas 114 isolates had gene for cap8, 76 isolates had gene for cap5. Ten isolates yielded negative results for both capsular polysaccharides. Only one agr type was detected in each isolate. One hundred and one isolates were agr type I, 47 isolates were type III, and 40 isolates were type II. None was positive for agr type IV. Twelve isolates yielded negative results for the four agr types tested.

The distribution of genes for SE, TSST-1 and PVL is summarized in Figure 1 and Table 2. In total, 142 (71.0\%) isolates were positive for SE, $8(4.0 \%)$ were positive for TSST1 and, 18 isolates, including the only MRSA isolate, were positive for PVL. Gene for SEI was the most common SE gene. It was detected in 77 isolates. Fifty isolates contained single SE genes, 54 isolates carried two SE genes, 28 and 10 isolates contained three and four SE genes respectively.
The characteristics of the 18 lukS-lukF positive isolates are presented in Table 3 . They had different resistance patterns, belonged to different agr and cap types and harbored different SE genes but none carried gene for TSST-1. When typed by PFGE to determine if they were related, they yielded eight PFGE patterns designated types A to $\mathrm{H}$ (Figure 2, Table 3). Eight isolates obtained from stool, hand and nasal samples had the same PFGE pattern (type A) and 10 isolates belonged to seven PFGE patterns.

When the isolates obtained during the screening exercise (screening samples) were compared with those obtained during routine investigation of food poisoning cases (routine samples), the results were not significantly different for the distribution of genes for agr and capsular polysaccharides (data not shown). Similarly, $72.9 \%$ of the screening sample isolates (97/133) and 67.1\% (45/67) of the routine samples isolates contained genes for SEs showing no significant difference in the distribution of genes for SE between the two sets of isolates ( $\mathrm{P}$ value $=0.50)$. Furthermore tst was detected in $5.2 \%(7 / 133)$ of the screening samples isolates and in $1.5 \%(1 / 67)$ of the routine sample isolates $(\mathrm{P}$ value $=0.4)$

\section{Discussion}

This study has demonstrated a high prevalence of antibacterial resistance and diversity in the carriage of virulence genes in $S$. aureus obtained from food handlers employed in restaurants in Kuwait City. Our results that $92.5 \%$ of the isolates expressed resistance to antibacterial agents is similar to the prevalence of antibacterial resistance in methicillin-susceptible $S$. aureus obtained from patients in Kuwait hospitals [24] and to that found in S. aureus isolates from food handlers in Chile [11] and Botswana [17]. Although only one isolate was methicillin-resistant, the finding is significant because food handlers carrying MRSA had initiated outbreaks in hospitals in the Netherlands [14], USA [25] and Brazil [15]. As food handlers represent a section of the healthy population in the com-

Table I: Distribution of genes for virulence factors in $200 \mathrm{~S}$. aureus isolated from food handlers.

\begin{tabular}{lllllllll}
\hline & \multicolumn{7}{c}{ Number (\%) of isolates positive for virulence genes } \\
\cline { 2 - 8 } Sources of S. aureus (\#) & SE & cap5 & cap8 & agr I & agr II & agrllI & lukS-lukF & tst \\
\hline Nose (I29) & $93(72.1)$ & $49(38.0)$ & $72(55.8)$ & $67(51.9)$ & $24(18.6)$ & $28(21.7)$ & II (8.5) & $7(5.4)$ \\
\hline Stool (3I) & $21(67.7)$ & $15(48.4)$ & $15(48.4)$ & $17(54.8)$ & $6(19.3)$ & $7(22.5)$ & $4(12.9)$ & $1(3.2)$ \\
\hline Hands (3I) & $22(70.9)$ & $9(29.0)$ & $21(67.7)$ & $13(41.9)$ & $6(19.3)$ & $11(34.0)$ & $3(9.7)$ & ND \\
\hline Throats (9) & $6(66.6)$ & $3(33.3)$ & $6(66.6)$ & $4(44.4)$ & $4(44.4)$ & $1(11.1)$ & ND & ND \\
\hline Total (200) & $142(71.0)$ & $76(38.0)$ & $114(57.0)$ & $101(50.5)$ & $40(20.0)$ & $47(23.5)$ & $18(9.0)$ & $8(4.0)$ \\
\hline
\end{tabular}

Abbreviations: cap, genes for capsular polysaccharide, agr, genes for accessory gene regulator, luKS-lukF genes for PVL, tst, genes for TSST-I. ND, Not detected 


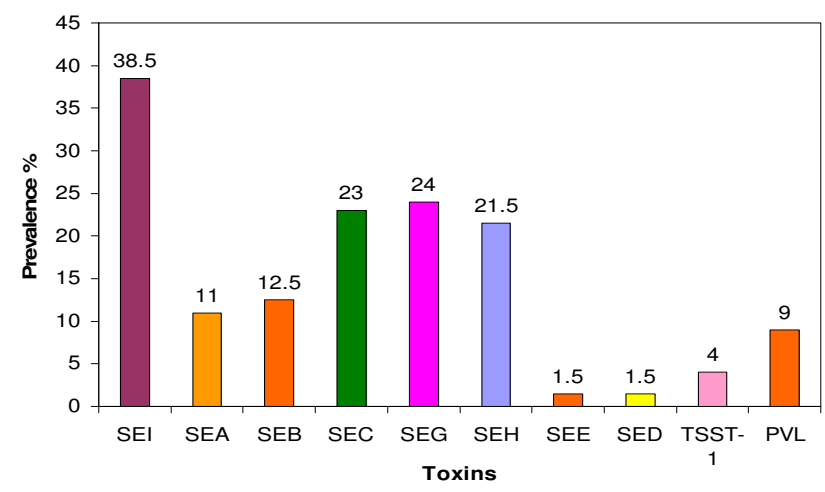

Figure I

Distribution of toxins in 200 S. aureus isolated from food handlers.

munity, besides working in restaurants, the detection of high prevalence of antibiotic resistance in $S$. aureus isolated from them also highlights the growing problem of antibiotic resistance in the community.

The ability of $S$. aureus to colonize or infect its host is related to its ability to express virulence factors that facilitate their adherence to surfaces, cause damage or its ability to evade host's immune system [1,2]. Our isolates carried genes for a range of virulence factors including three of the four accessory gene regulators that regulate staphylococcal virulence factors [6]. Our result that $50.5 \%$ of the isolates were agr type I concurs with results of other studies that the majority of $S$. aureus from clinical sources belong to agr type I [4,23]. Similarly, our results that $57 \%$ of the isolates belonged to serotype 8 and 38\% belonged to serotype 5 are in agreement with previous studies that showed

Table 2: Enterotoxin gene profiles of the 142 enterotoxinpositive $S$. aureus from food handlers.

Enterotoxin profiles

I S aureus isolates with single SE genes (50) sea (6), seb (9), sec (I3), seg (9), seh (6), sei (7)

2 S. aureus isolates with two SE genes (54) seg, sei (I3); seh, sei (I7); sea, sec (4); sec, seg (4); sec, seh (4); seb, seg (3); sea, sei (2); seb, sei (2); seg, sed (I); seb, sec (I); sec, sei (I); see, sei (I); seb, see (I).

3. S. aureus isolates with three SE genes (28) sec, seg, sei (9); sec, seh, sei (5); sea, seg, sei (4); seb, seg, sei (3); sea, seh, sei (3); seb, seh, sei (2);; sec, sed; seg (I); seb, sec, seg (I).

4 S. aureus isolates with four SE genes (10) sea, sec, seg, sei (3); sea, sec, seh, sei (I); seb, seg, seh, sei (I); seb, seg, seh, sei (I); seb, see, seh, sei (I); sea, seg, seh, sei (I); sea, sec, sed, seh(I); seb, sec, seh, sei (I).

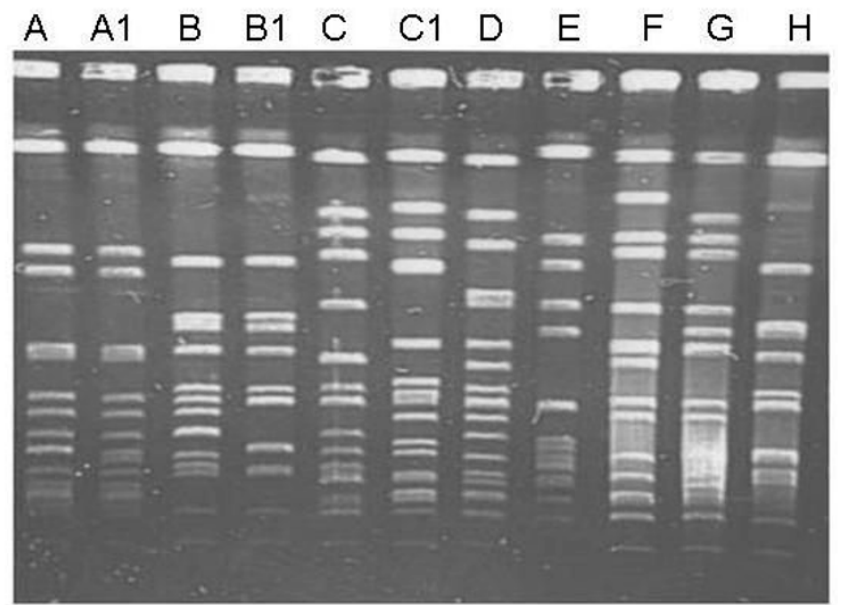

Figure 2

PFGE of representatives of I 8 PVL positive $S$. aureus from food handlers. Lanes A: PFGE type A, Lane AI: PFGE type AI, Lane B: PFGE type B, Lane BI: PFGE type BI, Lane C: PFGE type C, Lane CI: PFGE type CI, Lane D: PFGE type D, Lane E: PFGE type E, Lane G: PFGE type G, Lane H: PFGE type $\mathrm{H}$.

that the majority of $S$. aureus obtained from clinical samples belonged to capsular polysaccharide serotypes 5 or 8 $[2,23]$.

With regards to the carriage of SE determinants, the results of this study differ from that of a previous study in Kuwait [10]. The $71.0 \%$ prevalence of SE genes in this study was lower than the $86.6 \%$ prevalence detected previously in $S$. aureus from food handlers in Kuwait restaurants [10]. However, it was similar to the prevalence of $74.1 \%$ obtained from $S$. aureus isolated from food poisoning cases in Taiwan [26] and higher than the prevalence of SE reported in $S$. aureus from food handlers in Chile [19\%, [11]] and from humans, food and animal sources in Malaysia [20.8\%, [27]]. In addition, the demonstration of SEI as the most common SE gene in this study contrasted with the results of a previous study of SE in $S$. aureus isolated from food handlers in Kuwait restaurants [10] and other studies $[9,11,12]$ where SEA was the most common SE. Furthermore, whereas $64.7 \%$ of the SE positive isolates in this study carried genes for two to four SEs, only $8.6 \%$ of $S$. aureus in the previous study from Kuwait carried more than one SE gene [10]. This is consistent with recent reports in the literature that also document the carriage of multiple SE gene in enterotoxigenic $S$. aureus $[9,12,13]$. The detection of multiple SE genes in recent $S$. aureus isolates could be due to the improvement in detection methods following the application of PCR technology and the discovery of new SE genes which were not tested in the previous study. It could also be due to frequent horizontal transmission of phage-mediated toxin genes among the staphylococcal populations [21]. 
Table 3: Characteristics of I8 S. aureus isolates containing lukS-lukF

\begin{tabular}{|c|c|c|c|c|c|c|}
\hline Isolates & Source & Resistance pattern & agr class & cap type & SE genes & PFGE pattern \\
\hline $33 N$ & Nose & Pc, Tc, Tp, Cd & III & 8 & sea, sei & A \\
\hline $78 \mathrm{~N}$ & Nose & Mc, Pc, Km, Tc, Fd, Cd & III & 8 & ND & A \\
\hline $157 \mathrm{~N}$ & Nose & $\mathrm{Pc}, \mathrm{Km}, \mathrm{Sm}$ & III & 8 & Seg & $A$ \\
\hline $342 \mathrm{~N}$ & Nose & $\mathrm{Cd}$ & III & 8 & Sei & $\mathrm{Al}$ \\
\hline $515 N$ & Nose & $\mathrm{Cd}$ & III & 8 & ND & $\mathrm{H}$ \\
\hline $42 \mathrm{~N}$ & Nose & Pc, & 1 & 5 & seb, seh, sei & B \\
\hline $46 \mathrm{~N}$ & Nose & Pc, Sm & 1 & 5 & seh, sei & C \\
\hline $268 N$ & Nose & $\mathrm{Cd}$ & 1 & 8 & ND & C \\
\hline $298 \mathrm{~N}$ & Nose & Pc & 1 & 5 & seh & C \\
\hline $489 N$ & Nose & $\mathrm{Pc}, \mathrm{Cd}$ & 1 & 5 & seh, sei. & E \\
\hline $666 \mathrm{~N}$ & Nose & $\mathrm{Pc}, \mathrm{Tc}, \mathrm{Tp}, \mathrm{Cd}$ & 1 & 5 & sec, seg, sei. & G \\
\hline 9S & Stool & $\mathrm{Pc}, \mathrm{Tp}, \mathrm{Fd}$ & III & 8 & sea, seh, sei & A \\
\hline IOS & Stool & Pc, Tp & III & 8 & sea, seg, sei & $A$ \\
\hline $58 \mathrm{~S}$ & Stool & $\mathrm{Pc}, \mathrm{Tp}, \mathrm{Cd}$ & III & 8 & sea, sec, seg, sei & A \\
\hline $76 S$ & Stool & None & III & 8 & Seb & $\mathrm{D}$ \\
\hline $4 S$ & Hand & $\mathrm{Cd}$ & III & 8 & ND & $\mathrm{F}$ \\
\hline $515 S$ & Hand & Pc, Tc, Cd & III & 8 & seh, sei & A \\
\hline $666 \mathrm{~S}$ & Hand & Pc, Tc, Tp, Cd & I & 5 & sec, seg, sei. & B \\
\hline
\end{tabular}

Abbreviations: $\mathrm{Cd}$, cadmium acetate, Fd. fusidic acid. Km, kanamycin, Mc, methicillin, Pc, benzyl penicillin, Sm, streptomycin, Tc, tetracycline, Tp, trimethoprim, ND, not detected, agr, accessory gene regulator class, cap, capsular polysaccharide serotype type.

PVL is widely distributed among some clones of community-associated MRSA (CA-MRSA) isolated in Kuwait and other countries $[3,28,29]$ and was thought to contribute to the increased virulence of CA-MRSA isolates [3,28]. However, PVL has recently also been detected in healthcareassociated MRSA and in methicillin-susceptible $S$. aureus from patients [29]. Our report is the first in S. aureus obtained from food handlers in Kuwait and elsewhere. Its detection in $9.0 \%$ of the isolates in this study supports the suggestion that PVL-bearing phages are widespread among S. aureus of different genetic backgrounds and are not a specific characteristic of CA-MRSA $[19,29]$. The observation that eight of the 18 lukS-lukF positive isolates had same PFGE patterns suggested a transmission of a common strain among these workers. The detection of genes for PVL in $S$. aureus obtained from food handlers is of public health interest since these food handlers can serve as sources of transmission of PVL producing S. aureus in the community especially among family members.

Given that the majority of the isolates in this study contained genes for an array of virulence factors, they are potential causes of serious $S$. aureus infections. Therefore food handlers carrying these strains can contaminate food that can lead to food poisoning [7]. Thus, our results support the current practice of screening restaurant workers to identify $S$. aureus carriers and referring them to the appropriate health authorities for decolonization. Although the $S$. aureus carriage rate and their antibacterial resistance in this study may be similar to those found among healthy individuals in the general population [30], it is important to decontaminate food handlers carrying $S$. aureus because their exposure to, and possible contamination of food prepared and served in restaurants is a public health concern. 


\section{Conclusion}

This study has provided updated data on the carriage of SE and other virulence genes, and initial information on the prevalence of antibacterial resistance in $S$. aureus obtained from food handlers in restaurants in Kuwait and in the Gulf region. Our results should contribute to better management of $S$. aureus carriers among the food handlers and enhance the safety of restaurant customers.

\section{Competing interests}

The authors declare that they have no competing interests.

\section{Authors' contributions}

All authors conceived the study. SAM isolated and performed initial characterization of the isolates. EEU and MJA performed molecular characterization of the isolates. All authors participated in the preparation of the manuscript.

\section{Acknowledgements}

This study was supported by Kuwait University Research Grant No. MI 05/ 05. We thank Nadia Al Bania, B. Noronha and B. Mathew for technical assistance.

\section{References}

I. Dinges MM, Orwin PM, Schlievert PM: Exotoxins of Staphylococcus aureus. Clin Microbiol Rev 2000, 13:16-34.

2. O'Riordan K, Lee JC: Staphylococcus aureus capsular polysaccharides. Clin Microbiol Rev 2004, 17:2 I 8-234.

3. Lina G, Piemont Y, Godail-Gamot F, Bes M, Peter MO, Gauduchon V, Vandenesch F, Etienne J: Involvement of Panton-Valentine leukocidin producing Staphylococcus aureus in primary skin infections and pneumonia. Clin Infect Dis 1999, 29: | | 28- | | 32.

4. Jarraud S, Mougel C, Thiouluse J, Lina G, Meunier H, Forey F, Nesme X, Etienne J, Vandenesch F: Relationship between Staphylococcus aureus genetic background, virulence factors, agr type (alleles), and human disease type. Infect Immun 2002, 70:63I-64I.

5. Projan S], Novick RP: The molecular basis of pathogenicity. In The staphylococci in human disease Edited by: Crossley KB, Archer GL. Churchill Livingstone, New York, N.Y.; 1997:55-8I.

6. Jarraud S, Lyon G], Figueiredo AM, Lina G, Vandenesch F, Etienne J, Muir TW, Novick RP: Exfoliatin-producing strains define a four agr specificity group in Staphylococcus aureus. I Bacteriol 2000 182:6517-6522.

7. Colombari V, Mayer MD, Laicini ZM, Mamizuka E, Franco BD, Destro MT, Landgrave M: Foodborne outbreak caused by Staphylococcus aureus: phenotypic and genotypic characterization of strains of food and human sources. J Food Prot 2007, 70:489-493.

8. Mead PS, Slutsker L, Dietz V, McCaig LF, Bresee JS, Shapiro C, Griffin PM, Tauxe RV: Food-related illness and death in the United States. Emerg Infect Dis 1999, 5:607-625.

9. Cha JO, Lee JK, Jung YH, Yoo Jl, Park YK, Kim BS, Lee YS: Molecular analysis of Staphylococcal food poisoning in South Korea. J Appl Microbiol 2006, I 0 I:864-87I.

10. Al-Bustan MA, Udo EE, Chugh TD: Nasal carriage of enterotoxinproducing Staphylococcus aureus among restaurant workers in Kuwait City. Epidemiol Infect 1996, I I 6:319-322.

II. Figueroa G, Navarrete P, Caro M, Troncoso M, Faundez G: Carriage of enterotoxigenic Staphylococcus aureus in food handlers. Rev Med Chil 2002, I 30:859-864.

12. Holeckova B, Holoda E, Fotta M, Kalinacova V, Gondol J, Grolmus J: Occurrence of enterotoxigenic Staphylococcus aureus in food. Ann Agric Environ Med 2002, 9: 179-182.

13. Omoe K, Ishikawa M, Shimoda Y, Hu D-L, Ueda S, Shinagawa K: Detection of seg, seh, and sei genes in Staphylococcus aureus isolates and determination of the enterotoxins productivi- ties of S. aureus isolates harboring seg, seh, or sei genes. J Clin Microbiol 2002, 40:857-862.

14. Kluytmans J, van Rost Leeuwen W, Goessens W, Hollis R, Messer S, Herwaldt L, Bruining H, Heck MJ, van Leeuwen N, van Belkum A, Verbrugh H: Food-initiated outbreak of methicillin-resistant Staphylococcus aureus analyzed by phenol-and genotyping. J Clin Microbiol 1995, 33: I I21-II28.

15. Soares MJ, Tokumaru-Miyazaki NH, Noleto AL, Figueiredo AM: Enterotoxin production by Staphylococcus aureus clones and detection of Brazilian epidemic MRSA clone (III::B:A) among isolates from food handlers. I Med Microbiol 1997, 46:2|4-22|.

16. Udo EE, Al-Bustan MA, Jacob LE, Chugh TD: Enterotoxin production by coagulase-negative staphylococci in restaurant workers from Kuwait City may be a potential cause of food poisoning. J Med Microbiol 1999, 48:819-823.

17. Loeto D, Matsheka MI, Gashe BA: Enterotoxigenic and antibiotic resistance determination of Staphylococcus aureus strains isolated from food handlers in Gaborone, Botswana. J Food Prot 2007, 70:2764-2768.

18. National Committee for Clinical Laboratory Standards: Performance for disk diffusion susceptibility tests. Approved Standards. National Committee for Clinical Laboratory Standards. Wayne, Pa 2000.

19. Udo EE, Farook VS, Mokadas EM, Jacob LE, Sanyal SC: Molecular fingerprinting of mupirocin-resistant Staphylococcus aureus from a Burn unit. Int J Infect Dis 1999, 3:82-87.

20. Becker K, Roth R, Peters G: Rapid and specific detection of toxigenic Staphylococcus aureus: use of two multiplex PCR enzyme immunoassays for amplification and hybridization of staphylococcal enterotoxins genes, exfoliative toxins, and toxic shock syndrome toxin I gene. J Clin Microbiol 1998, 36:2548-2553.

21. Monday SR, Bohach GA: Use of multiplex PCR to detect classical and newly described pyrogenic exotoxins in Staphylococcal isolates. J Clin Microbiol 1999, 37:34 I I-34I4

22. Lina G, Boutite F, Tristan A, Bes M, Etienne J, Vandenesch F: Bacterial competition for human nasal cavity colonization: role of staphylococcal agr alleles. Appl Environ Microbiol 2003, 69:18-23.

23. Moore PCL, Lindsay JA: Genetic variation among hospital isolates of methicillin-sensitive Staphylococcus aureus: evidence for horizontal transfer of virulence genes. J Clin Microbiol $200 \mathrm{I}$, 39:2760-2767.

24. Udo EE, Al-Sweih N, Dhar R, Dimnitrov TS, Mokaddas EM, Johny M, Al-Obaid IA, Gomaa HH, Mobasher LA, Rotimi VO, Al-Asar A: Surveillance of antibacterial resistance in Staphylococcus aureus isolated in Kuwait hospitals. Med Princ Pract 2008, 17:71-75.

25. Jones TF, Kellum ME, Porter SS, Bell M, Schaffner W: An outbreak of community-acquired foodborne illness caused by methicillin-resistant Staphylococcus aureus. Emerg Infect Dis 2002, 8:82-84

26. Chiang YC, Lin CW, Yang CY, Tsen HY: PCR primers for the detection of staphylococcal enterotoxin $K$, $L$, and $M$ and survey of staphylococcal enterotoxin types in Staphylococcus aureus isolates from food poisoning cases in Taiwan. J Food Prot 2006, 69:1072-1079.

27. Lim YS, Jegathesan M, Koay AS: Enterotoxin production by Staphylococcus aureus strains isolated from humans, food and animals in Malaysia. Southeast Asia J Trop Med Public Health 1982, 13:133-137.

28. Udo EE, O'Brien FG, AI-Sweih N, Noronha B, Mathew B, Grubb WB: Genetic lineages of community-associated methicillin-resistant Staphylococcus aureus in Kuwait hospitals. J Clin Microbiol 2008, 46:35|4-35|6.

29. Monecke S, Stickers P, Ellington MJ, Kearns AM, Ehricht R: High diversity of Panton-Valentine leukocidin-positive, methicillin-susceptible isolates Staphylococcus aureus and implications for the evolution of community-associated methicillinresistant S. aureus. Clin Microbiol Infect 2007, 1 3: | | 57- I I 64.

30. Mainous AG, Hueston W], Everet C], Diaz VA: Nasal carriage of Staphylococcus aureus and methicillin-resistant $S$. aureus in the United States, 200I-2002. Ann Fam Med 2006, 4:I32-I 37. 